\title{
An agenda for neuroeducation: relating psychophysiological and behavioral data across time scales of learning
}

\author{
https://doi.org/10.24046/neuroed.20130201.71
}

\section{Julien MERCIER ${ }^{1,{ }^{*}}$ and Patrick CHARLAND ${ }^{1}$}

\author{
1 Université du Québec à Montréal \\ *Email: mercier.julien@uqam.ca
}

\begin{abstract}
Research on learning has previously focused on changes in knowledge and behavior occurring over long periods of time, such as over a period of hours, weeks, months and years. However, there is no doubt that learning-contingent changes in knowledge and behavior are mediated by neural processes occurring at much shorter timeframes (e.g., milliseconds), including the time between a single observable behavioral event, that help determine whether learning occurs. In addition, current applied research in education requires experimentation and assessment in authentic contexts within which learning and performance take place in order to provide ecologically valid results with respect to contemporary contexts that involve social interaction. We argue that it is now time for the field of neuroeducation to relate psychophysiological and behavioral data across time scales. Globally, a better understanding of the underlying cognitive processes occurring during different components of learning. This should lead to novel learning environments, greater and more efficient interactivity between teacher and learner(s), better assessment tools leading to qualitatively and quantitatively better development of knowledge and skills in key domains such as teaching, business, health professions, engineering as well as other domains targeting human development and well-being. Along these lines, this paper presents a research program oriented towards the modeling of learning trajectories and performance at psychophysiological, cognitive and social levels. The projected research findings should allow for more significant understandings of the implication of cognitive neuroscience in education by linking results with more authentic learning and performance situations.
\end{abstract}




\section{Introduction}

Neuroeducation is a very dynamic field despite its relatively short history. We share the enthusiasm of many authors regarding the potential of this research for the improvement of learning. However, we are much more circumspect regarding its impact to date. Neuroeducation has been informative on crucial aspects of learning not tractable using traditional approaches in education. Notably, this field has shed new light on aspects of learning to read (Hruby, Goswami, Frederiksen, \& Perfetti, 2011) and mathematics (Grabner \& De Smedt, 2012). However, so far, the nature of these findings makes it difficult to translate them into prescriptions for educational practice (Hruby, 2012). The long-recognized divide between the contexts of experiments and the contexts of application of their results may just resurface abruptly with the advent of neuroeducational research (Ansari, Coch, \& De Smedt, 2011; Turner, 2012). In contrast, research in applied cognitive science has led to an unprecedented set of implications in education, including for example how people take charge of their learning (Greene \& Azevedo, 2010), how interactions with peers are beneficial or detrimental to learning (Kirschner, Paas, \& Kirschner, 2011) and how a domain expert or a computer-based learning environment can foster learning through tutoring (VanLehn, 2011). However, these studies hinge on behavioral records of human action, and do not consider psychophysiological data, which can provide important complementary information. In sum, the objectives and means of behavioral studies in cognitive science on the one hand and cognitive neuroscience on the other hand are partly tangential to the type of research in neuroeducation advocated in this paper. The potential and limitations of their integration should be explored now that the field is being defined in terms of theoretical foundations, methodological approaches and research questions (Ansari et al., 2011).

Most of the research on learning has so far focused on changes in knowledge and behavior occurring over long periods of time, such as over a period of hours, weeks, months and years. However, learning-contingent changes in knowledge and behavior are mediated by neural processes occurring at much shorter timeframes (e.g. milliseconds), including the time between a single observable behavioral event, that help determine whether learning occurs (Anderson, 2002; Fincham, Anderson, Betts, \& Ferris, 2010). Furthermore, every moment during which a teacher interacts with a student, he/she makes decisions about the provision of support such as scaffolding and feedback that influence learning efficacy (VanLehn, 2011). Indeed, events occurring at the grain size of social interaction are related to events occurring at the grain size of learning (Anderson, 2002). 
Research in education is at a turning point where approaches and protocols can inform us about optimal interventions at this level of interaction so that the teachers can be supported to make better decisions during studentteacher interactions (Kent, 2013).

Which principles, mechanisms and theories studied in educational research can be extended on the basis of findings from cognitive neuroscience? Which principles, mechanisms and theories studied in cognitive neuroscience might have implications for educational research? What research questions can be developed on the basis of these implications? What form could an interdisciplinary or transdisciplinary research program take? (de Jong et al., 2009, p. 2).

Research in neuroeducation can contribute answers to these questions by conducting studies through innovative methodology in education by engaging in dialogue with researchers from other pertinent fields involving cognitive neuroscience, such as neuroergonomics because of its focus on natural performance situations (see Parasuraman, 2012; Posner, 2012). These answers should have a profound impact on how learning is understood and on how learning environments are designed and implemented for academic and professional learning. By hinging on a better understanding of learning, such learning environments could offer a greater interactivity, and even reactivity to the learner by incorporating better assessment tools leading to qualitatively and quantitatively enhanced development of knowledge and skills in key domains such as business, health professions, the military, engineering as well as teaching and other domains targeting human development and well-being. The view presented complements and extends current approaches from cognitive neuroscience in education. The aim of this paper is to present theoretical and methodological prescriptions for the field of neuroeducation that can fruitfully complement existing research and to provide an illustration of the advocated program of research through a presentation of a study in preparation.

\section{A framework for a neuroeducational research program oriented on time scales}

Projected research can be shortly described as adding a psychophysiological layer to existing empirical cognitive research on learning, sometimes in situations involving human interactions. This research program can be defined as the concomitant study of psychophysiological, cognitive, and even social aspects of learning. It has the following question at its core: How does learning arise from psychophysiological, cognitive and social cognitive processes during learning interactions? 
The development of this research agenda requires major efforts in three synergistic aspects: (1) the development of theoretical foundations (2) the development and testing of research methodology and (3) conducting empirical research.

\subsection{Developing theoretical foundations}

The development of theoretical foundations in neuroeducation involves the amalgam of existing theories describing (1) cognitive functioning, (2) the psychophysiological substrates of behavior and learning, and (3) the social processes of learning situations. The resulting view borrows from diverse disciplines including, but not limited to, education, educational psychology, cognitive psychology, cognitive neuroscience, and social neuroscience.

According to many authors (Anderson, 2002; Fincham et al., 2010; Newell, 1990; Sun, 2006), the questions of what is learning and how to foster this process can only be understood completely using a multi-layered view of human behavior and a reciprocal interaction of various processes. Based on actual work in cognitive modeling, this perspective also posits that all levels below a given level are necessary to explain functioning at that level (Newell, 1990). This raises new questions: what are the psychophysiological signatures of learning? What are the psychophysiological signatures of productive cooperation in group learning tasks (at the group level and at the individual level)? What is going on in people's mind when they are not talking during group work in learning situations? How can we make group work in learning tasks as efficient as individual learning while achieving learning results greater than the sum of its parts? Mercier, Léger, Girard, and Dion (2012) summarized the data and processes that will be put in relation in unique ways in the projected research.

At this time, we have identified specific domain-generic processes that are relevant to learning and amenable to valid psychophysiological measurement in authentic learning contexts. These processes include cognitive load (Antonenko, Paas, Garbner, \& van Gog, 2010), task engagement (Freeman, Mikulka, Scerbo, \& Scott, 2004), drowsiness/alertness (Stikic et al., 2011) as well as attention (Klimesch, Doppelmayr, Russegger, Pachinger, \& Schwaiger, 1998) and emotions (Fulmer \& Frijters, 2009).

\subsection{Developing research methodologies}

A second aspect of the research program is the development and testing of new experimental protocols associated with the use of electroencephalography (EEG) and adapted to an ecologically-valid 
educational context in which naturalistic interactions occur over extended periods of time. This involves obtaining interpretable data from psychophysiological measurements. Operations needed to obtain finegrained state data of brain activation associated with cognitive functions within social interactions in learning contexts include decontamination algorithms, signal transformation, and the mapping of activation patterns with low-level (in the sense of high temporal resolution) cognitive functions. We propose that this is best achieved by analyzing EEG data from the perspective of characterizing the brain activation at specific sites over time. This approach is referred to as the time-frequency analysis of EEG data (Roach \& Mathalon, 2008). Spectral decomposition of oscillatory patterns in neuronal activity - determining which frequency is present for a given period and its power - coupled with the localization of the source of this activity, is indicative of brain functions that occurred during that period. Four frequency bands are commonly used in the interpretation of EEG data in this manner: delta $(<4 \mathrm{~Hz})$, theta $(4-7 \mathrm{~Hz})$ alpha $(8-13 \mathrm{~Hz})$ and beta $(>13 \mathrm{~Hz})$.

For exemple, Pope, Bogard and Bartolome (1995) developed a task where a subject would be either solicited by a system (manual mode) or not (automatic mode). Collecting EEG signal and comparing mental states during manual (engaged) mode versus automatic (disengaged) modes, Pope's team tested multiple ratio candidate that would better fit the two conditions, based on the vigilance literature (Davidson, 1988; Lubar, 1991; Offenloch \& Zanner, 1990). They established the best index of mental engagement to a task related to the sum of powers of beta / (alpha+theta) of EEG signal collected at the sites Cz, Pz, P3 and P4 on a 10-20 montage. This index of engagement was also validated in the field of neuroergonomics, in the work of Freeman, Mikulka, Prinzel, and Scerbo (1999), Freeman et al. (2004) and Mikulka, Scerbo, and Freeman. (2002). Transferred to neuroeducation, the value of this approach lies in the possibility to extract educationally-relevant information from psychophysiological data during the course of human action in a learning activity as traditionally recorded in applied cognitive science. By focusing on different system levels and time scales and the relationship between them, this approach may also contribute to bridging existing laboratory results focusing on short-term processes with instructional practice as understood by its practitioners.

Another methodological development involves designing strategies for integrated data analysis, such as intra- and inter-level sequential, cooccurrence, and prevalence approaches, applied to shorter and shorter time scales (see Kapur, 2011). Although not essential, designing methods for automated data analysis should be actively pursued to boost the production of results. Extracting fine-grained state data from each "numerical" data 
source using algorithms derived from large populations of subjects seems worthwhile and more feasible with levels of analysis of a more "semantic" nature, such as speech and interaction, as current research on intelligent tutoring systems shows (Chi, VanLehn, Litman, \& Jordan, 2011).

EEG source imaging has made tremendous progress in recent years to provide neurophysiological interpretations of scalp recordings (Astolfi et al., 2010). By showing the location of activation, source analysis brings additional explanatory power to EEG measurements and is now becoming the norm in the use of EEG in cognitive neuroscience. When no a priori assumptions can be made regarding the localization of activation (as it is practically the case in the study of learning interactions), mathematical solutions can be used effectively to determine (1) when brain activation maps differ over time, thus segmenting microstates representing relatively stable brain activation patterns and (2) the localization of brain activation during those microstates (Lehmann, Osaki, \& Pal, 1987). Those microstates have explanatory power and represent functional "mind-states" during information-processing. They have to be further interpreted by the fine-grained localization of brain activity using recent event-related potential (ERP) studies, representing cognitive functions responsible for learning (e.g. social learning, metacognitive regulation in problem solving, insight in problem solving, implicit and explicit learning, etc. (see de Jong et al., 2009)). This interpretation relies critically on sufficient spatial sampling. For brain activity sampled at $1000 \mathrm{~Hz}$, it is possible to extract discrete brain states of between 80 and 120 milliseconds by statistical estimation (Lehmann \& Michel, 2011). Such microstates, and especially how they get modulated both in terms of sequence and duration, can be related to cognitive and interpersonal events (Grafton \& Tipper, 2012). The study of these microstates represents aspects of the answer to the first question: what is the neurophysiological signature of learning?

\subsection{Conducting empirical research}

Projected empirical research will be conducted to provide elements of answer to three main interrelated questions focusing on how sequences of events caused learning (the so-called precursors referring to both antecedents or cooccurring events): (1) What is the psychophysiological signature of learning? (2) What are the cognitive precursors of learning? (3) What are the social precursors of learning? Without answers to these three questions, it is not possible to know precisely when learning occurred and why it happened in authentic contexts, either from a cognitive or social (human interaction) point of view, since those contexts routinely involve self-directed and supervised learning activities. The strategy involves using psychophysiological methods in authentic contexts in conjunction with all available precautions and 
pertinent analytical approaches to minimize measurement flaws associated with those contexts (Gevins, Chan, \& Sam-Vargas, 2012). Contextual factors in which the studies will be positioned can be mapped onto various dimensions pertaining to how dyads of learners or a teacher and student interact, including how pertinent knowledge is distributed across individuals.

\subsubsection{Proof of concept from the field of human factors}

Much of recent teamwork research has used externalized events focusing on who is a member of the team, how they work together and what they do to perform their work. There have been fewer studies looking at the complex dynamics of how teamwork interactions unfold (Mathieu, Maynard, Rapp, \& Gilson, 2008). Macrocognition (Warner, Letsky, \& Cowen, 2005) is one framework for studying team interactions, and is defined as the externalized and internalized high-level mental processes employed by teams to create new knowledge. To its extreme, macrocognition involves considering a small group (constituted of three or more people who interact directly) as a single, unified thinking system. External processes are those associated with observable actions and measurable in a consistent, reliable, repeatable manner. Internalized processes are indirectly approached through qualitative metrics like think aloud protocols or surrogate quantitative metrics like pupil size, EEG or skin conductance. Speech provides a detailed and dynamic representation of teamwork. When team members interact, their communication streams contain information about knowledge, uncertainty, awareness of the situation, stress and other cognitive states (Cooke, Gorman, \& Kiekel, 2008). Speech has structure in the content of what is being said, in flow, and relating to who is speaking along with specific speech functions. Speech is also sequential, temporal and relational as people tend to speak one after another and what is currently being said has temporal antecedents (Gorman, 2005). Communication streams and other non-verbal behavioral data are central for studying teamwork, yet additional measures would be useful which are relevant, unobtrusive, obtained in real-time, and can be practically implemented (Salas, Cook, \& Rosen, 2008).

Newly available psychophysiological approaches are providing such measures. Across multiple teamwork tasks, Stevens, Galloway, Berka, and Behneman (2010) found that psychophysiological patterns were shown to be non-random and sensitive to changes in the task and the activities of team members. These studies suggest that neurophysiologic correlates measured by EEG may be useful for studying team behavior not only at the milliseconds level, but at more extended time frames. Stevens, Galloway, Wang, and Berka (2011) more recently argued that neurophysiological data may complement communication metrics as measures of group cognition. 
Projected research builds on these breakthroughs in the field of human factors and relates them to a single, dramatically important variable: learning.

\subsubsection{An example of a study: a teacher coaching a student in classic problem- based learning}

Many perspectives have shown that the success of tutorial interaction for learning depends essentially on the contingency of the help on the learner's needs (Fincham et al., 2010; Wood \& Wood, 1999; VanLehn, 2011). This contingency depends on the moment-to-moment interaction between the tutor and the tutee(s) during the learning activity. In our opinion, this important phenomenon has been studied in research of exceptional quality regarding the functional aspect of discourse. Our extensive literature review suggests that the underlying brain activity has been much less, insufficiently studied in the learner, not studied in the tutor, and even less concomitantly in both during the course of a tutorial interaction. Indeed, these studies are based on conversation data, which represent partial records of participants' cognitive activity since obviously they cannot all speak at the same time. The overarching goal of this study is to further test and contribute to theory regarding tutorial interaction, reputedly the most effective teaching method since 25 years (VanLehn, 2011).

As a starting point, a study in preparation will further examine the causes of this efficiency as this type of tutorial interaction unfolds in classic problembased learning (PBL). PBL is a situation extended in time over a few sessions in which a group of students learn with the help of a coach on the basis of jointly-determined "learning issues" (Barrows, 1986). PBL is widely used worldwide in higher education, particularly in medical education. The causes of this efficacy pertaining to the interaction are still intricate and can involve the tutor's initiative, the learners' initiative, or their joint initiative (Chi, Siler, Jeong, Yamauchi, \& Hausmann, 2001). Answers to a vast quantity of critical questions including the following cannot be obtained by relying only on conversational data: How accurate is the teacher monitoring of students' learning state? What is the impact of answering the question of one student on the other students? What is the impact of inter-student conversation? What is the impact of "classroom" processes on the teacher thought processes?

Through a multi-level view of cognition (Newell, 1990) centered on learning (Anderson, 2002) which postulated functional relations between brain activity, cognitive functioning and social interaction (Sun, 2006), this study will examine how intra- and inter-level relations determine the regulation of interindividual interactions in a learning context as well as their effects on 
students' learning. Five two-hour tutoring sessions, part of a regular physics class at UQAM will be videotaped. Electroencephalography will be recorded for the student and his coach. The orientation and sharing of their attention will be established through eye-tracking goggles. All data will be synchronized to the 1000th of second. The analysis will establish the intra and interindividual, as well as intra and inter-level (psychophysiological, cognitive, and social) sequential dependencies. The following questions represent the framework for data analysis.

What is the best tutorial interaction as determined by psychophysiological, cognitive and social processes? The first questions have to be answered separately for each level (psychophysiological, cognitive, social) for each individual in the learning interaction before answering the second question. Because it is the most substantiated by theory, the cognitive level serves as the "anchor" in the analysis. The first question is : (1) What are the indicators of contingency of tutor help on learners' needs in tutoring? This question is broken down into three sub-questions: (1.1) What are the indicators of decision-making in the coach (diagnosis of learners' state, planning of tutorial moves, and evaluation of enacted moves)? (1.2) What are the indicators of learners' difficulties and success in problem-solving? and (1.3) What are the relationships between these indicators and learning results? Elements of answer to all these questions are then put in relation in answering the second main question: (2) What is the correspondence between psychophysiological, cognitive, and social indicators of contingency in tutoring interaction?

Briefly, the analysis of the neural data involves preserving the synchronization of the data for all levels, the identification of critical events on the basis of theory of tutoring, the specification of brain regions likely to be associated with these events (either confirmatory or exploratory) and finally to establish the intra and inter-level and intra and inter-individual causal correspondences on the basis of the temporal co-occurrence of events associated with every "trace".

Answers to the aforementioned questions should contribute to develop tutoring skills in educators by giving them additional keys to interpret their student's behavior and talk during learning interactions. These results should also begin to show the potential and pitfalls of student-modeling based on psychophysiological tracing for human tutors and later, for next-generation intelligent tutoring systems. 


\section{Conclusion}

This article presented a general framework that can contribute in the development of bridges between educational and neuroscientific research. We strongly believe that researchers in neuroeducation can establish new research perspectives regarding how people learn, including in social contexts, by getting access to more complete information about the human mind across the multiple time scales pertinent to explain learning. While neural correlates of learning present high potential for the study of beneficial and detrimental conditions for learning, the vast majority of the best studies of learning rely on inferences about brain functioning based on behavior. The shortcoming of such inferences resides in the simple fact that psychophysiological processes occur faster than anything than can be measured behaviorally. By the direct access to brain activity in learning contexts that can even include social interaction, the assumptions regarding the psychophysiological level can be empirically tested. In our opinion, the key questions identified before are among the most central that the field of neuroeducation has to address. The framework associated with those questions can be further operationalized using pertinent concepts and methods to connect with current topics in learning and instruction. Examples of such topics for which research as envisioned here can be undertaken at the present include cognitive load (Antonenko et al., 2010), engagement during learning tasks (Freeman et al., 2004; Charland, Allaire-Duquette, \& Léger, 2012), and human and computer tutoring (Mercier \& Charland, submitted). At the moment, spectral analysis of EEG data is the approach of choice for this research, but current advances in single-trial in P300 classification are likely to provide additional alternatives (Debener, Minow, Emkes, Gandras, \& de Vos, 2012; Mattout, 2012). In this context, it is encouraging to note that recent experiments with portable EEG suggest that gains in ecological validity outweigh losses in measurement quality (Gevins et al., 2012; Debener et al., 2012). After many decades of theorizing and formulating promises about this kind of research, the time has finally come where it is possible to conduct high-potential research in education involving the integration of psychophysiological and behavioral data. Technological developments in the acquisition and analysis of psychophysiological data have recently led to the availability of appropriate equipment.

Because of the inherently complex nature of most learning situations, it is imperative that research in neuroeducation be grounded in authentic and even interactive contexts to have its full impact on fostering learning. The view presented can contribute to forge aspects of the missing bridge between research in education and research in neuroeducation. Thus, fostering the impact of neuroeducation in educational practice involves the specification of 
contexts and social interactions most critical to learning and most common in learning contexts and the study of their psychophysiological and behavioral aspects. It is now time to begin developing the expected theoretical, methodological, and empirical advances in order to foster theoretically-driven and empirically-based educational implications of neuroeducational research. This work was not possible until very recently.

Projected research will have applications at different levels of instructional design and will be determinant in inventing the learning environments of the $21^{\text {st }}$ century. The findings of the proposed research should lead to the design of radically new learning environments involving teachers, instructors, and learning software. These environments will have increased potential to be optimally contingent on the learners' needs, which are transitioning rapidly during the course of a learning task, during a school day, and across learning domains. Contingency, the dynamic matching of the learning environment and the learner's state, inherently imply that the more temporally fine-grained characterization of the learner's cognitive state will make possible very finegrained adaptations of the learning environment in terms of moment-bymoment instantiations of specific modes of scaffolding and feedback, which will lead to more learning. Teaching interactions - whether in the classroom or distance learning - will be improved by mapping characteristics of the interaction with their non-behavioral fine-grained impact on learning (information on processing by the student(s) and teacher that does not disrupt the natural interaction) so that learning inductive conversation patterns can be identified and reproduced in face-to-face or technology-mediated interaction. Learning activities will be better designed given novel information regarding learners' cognitive processing during those tasks (for example, engagement and cognitive load) coupled with performance measures during these activities. Learning materials will be better constructed by "customizing" them with the learner needs as measured by processing and related with student cognitive behavior. Finally, as a specific case, the development of interactive learning environments would benefit from these data to reinforce both the expert module (how the knowledge is represented in the system) and diagnosis module (how the learner's needs are determined), as well as the planning module (how instruction is sequenced) and teaching module (how the knowledge is presented to the learner) that would in turn serve as research environments regarding the mapping of constraints between the psychophysiological, cognitive and social aspects of learning and performance. The research will require a long time and coordinated efforts from a substantial number of researchers. It is hoped that the perspective outlined and the themes identified will help foster the necessary bridges between educational research and neuroeducation. 


\section{References}

Anderson, J. R. (2002). Spanning seven orders of magnitude: A challenge for cognitive modeling. Cognitive Science, 26(1), 85-112.

https://doi.org/10.1207/s15516709 $\operatorname{cog} 26013$

Ansari, D., Coch, D., \& De Smedt, B. (2011). Connecting Education and Cognitive Neuroscience: Where will the journey take us? Educational Philosophy and Theory, 43(1), 37-42.

https://doi.org/10.1111/j.1469-5812.2010.00705.x

Antonenko, P., Paas, F., Grabner, R., \& van Gog, T. (2010). Using electroencephalography to measure cognitive load. Educational Psychology Review, 22(4), 425-438. https://doi.org/10.1007/s10648010-9130-y

Astolfi, L., Cincotti, F., Mattia, D., De Vico Fallani, F., Vecciato, G., Salinari, S., ... Babiloni, F. (2010). Time-varying cortical connectivity estimation from noninvasive, high-resolution EEG recordings. Journal of Psychophysiology, 24(2), 83-90. https://doi.org/10.1027/0269-8803/a000017

Barrows, H. S. (1986). A taxonomy of problem-based learning methods. Medical Education, 20(6), 481-486. https://doi.org/10.1111/j.13652923.1986.tb01386.x

Charland, P., Allaire-Duquette, G. et Léger, P. M. (2012). Collecting neurophysiological data to investigate users' cognitive state during game play. Journal on Computing, 2(3), 20-24. https://doi.org/10.1037/e525192013-005

Chi, M., VanLehn, K., Litman, D., \& Jordan, P. (2011). Empirically evaluating the application of reinforcement learning to the induction of effective and adaptive pedagogical strategies. User Modeling and User-Adapted Interaction, 21(1-2), 137-180. https://doi.org/10.1007/s11257-0109093-1

Chi, M. T. H., Siler, S. A., Jeong, H., Yamauchi, T., \& Hausmann, R. G. (2001). Learning from human tutoring. Cognitive Science, 25(4), 471534. https://doi.org/10.1016/s0364-0213(01)00044-1

Cooke, N. J., Gorman, J. C., \& Kiekel, P. A. (2008) Communication as teamlevel cognitive process. In M. P. Letsky, N. W. Warner, C. A. P. Smith (Eds.), Macrocognition in teams: Theories and methodologies (pp. 5164). Farnham, UK: Ashgate Publishing.

Davidson, R. J. (1988). EEG measures of cerebral asymmetry: Conceptual and methodological issues. International Journal of Neuroscience, 39(1-2), 71-89. https://doi.org/10.3109/00207458808985694 
Debener, S., Minow, F., Emkes, R., Gandras, K., \& de Vos, M. (2012). How about taking a low-cost, small, and wireless EEG for a walk? Psychophysiology, 49(11), 1617-1621. https://doi.org/10.1111/j.14698986.2012.01471.x

De Jong, T., Van Gog, T., Jenks, K., Manlove, S., van Hell, J. J., van Merriënboer, J. J. G., van Leeuwen, T., \& Boschloo, A. (2009). Explorations in learning and the brain: On the potential of Cognitive Neuroscience for Educational Science. The Hague, Netherlands: Organisation for Scientific Research.

Fincham, J. M., Anderson, J. R., Betts, S. A., \& Ferris, J. L. (2010). Using neural imaging and cognitive modeling to infer mental states while using an intelligent tutoring system. In Proceedings of the Third International Conference on Educational Data Mining (EDM2010), July 11-13, Pittsburgh, PA.

Freeman, F. G., Mikulka, P. J., Prinzel, L. J., \& Scerbo, M. W. (1999). Evaluation of an adaptive automation system using three EEG indices with a visual tracking task. Biological Psychology, 50(1), 61-76. https://doi.org/10.1016/s0301-0511(99)00002-2

Freeman, F. G., Mikulka, P. J., Scerbo, M. W., \& Scott, L. (2004). An evaluation of an adaptive automation system using a cognitive vigilance task. Biological Psychology, 67(3), 283-297. https://doi.org/10.1016/j.biopsycho.2004.01.002

Fulmer, S. M., \& Frijters, J. C. (2009). A review of self-report and alternative approaches in the measurement of student motivation. Educational Psychology Review, 21(3), 219-246. https://doi.org/10.1007/s10648009-9107-X

Gevins, A., Chan, C. S., \& Sam-Vargas, L. (2012). Towards measuring brain function on groups of people in the real world. PLOS ONE, 7(9), e44676. https://doi.org/10.1371/journal.pone.0044676

Gorman, J. C. (2005). The concept of long memory for assessing the global effects of augmented team cognition. Proceedings of the 11th International Conference on Human-Computer Interaction, July 22-27, Las Vegas, NV.

Grabner, R. H. \& De Smedt, B. (2012). Oscillatory EEG correlates of arithmetic strategies: a training study. Frontiers in Psychology, 3, 1-11. https://doi.org/10.3389/fpsyg.2012.00428

Grafton, S. T. \& Tipper, C. M. (2012). Decoding intention: A neuroergonomic perspective. Neurolmage, 59(1), 14-24.

https://doi.org/10.1016/j.neuroimage.2011.05.064 
Greene, J. A., \& Azevedo, R. (2010). The measurement of learners' selfregulated cognitive and metacognitive processes while using computer-based learning environments. Educational Psychologist, 45(4), 203-209. https://doi.org/10.1080/00461520.2010.515935

Hruby, G. G. (2012). Three requirements for justifying an educational neuroscience. British Journal of Educational Psychology, 82(1), 1-23. https://doi.org/10.1111//.2044-8279.2012.02068.x

Hruby, G. G, Goswami, U., Frederiksen, C. H., \& Perfetti, C. A. (2011). Neuroscience and reading: A review for reading education researchers. Reading Research Quarterly, 46(2), 156-172. https://doi.org/10.1598/rrq.46.2.4

Kapur, M. (2011). Temporality matters: Advancing a method for analyzing problem-solving processes in a computer-supported collaborative environment. Computer-Supported Collaborative Learning, 6(1), 39-56. https://doi.org/10.1007/s11412-011-9109-9

Kent, A. (2013). Synchronization as a classroom dynamic: A practitioner's perspective. Mind, Brain, \& Education, 7(1), 13-18. https://doi.org/10.1111/mbe.12002

Kirschner, F., Paas, F., \& Kirschner, P. A. (2011). Task complexity as a driver for collaborative learning efficiency: The collective working-memory effect. Applied Cognitive Psychology, 25(4), 615-624.

https://doi.org/10.1002/acp.1730

Klimesch, W., Doppelmayr, M., Russegger, H., Pachinger, T., \& Schwaiger, J. (1998). Induced alpha band power changes in the human EEG and attention. Neuroscience Letters, 244(2), 73-76. https://doi.org/10.1016/s0304-3940(98)00122-0

Lehmann, D., \& Michel, C. M. (2011). EEG-defined functional microstates as basic building blocks of mental processes. Clinical Neurophysiology, 122(6), 1073-1074. https://doi.org/10.1016/j.clinph.2010.11.003

Lehmann, D., Ozaki, H., \& Pal, I. (1987). EEG alpha map series: Brain microstates by space-oriented adaptive segmentation. Electroencephalography Clinical Neurophysiology, 67(3), 271-288. https://doi.org/10.1016/0013-4694(87)90025-3

Lubar, J. F. (1991). Discourse on the development of EEG diagnostics and biofeedback for attention-deficit/hyperactivity disorders. Biofeedback and Self-Regulation, 16(3), 201-225. https://doi.org/10.1007/bf01000016 
Mathieu, J., Maynard, M. T., Rapp, T., \& Gilson, L. (2008). Team effectiveness 1997-2007: A review of recent advancements and a glimpse into the future. Journal of Management, 34(3), 410-476. https://doi.org/10.1177/0149206308316061

Mattout, J. (2012). Brain-computer interfaces: A neuroscience paradigm of social interaction? A matter of perspective. Frontiers in Human Neuroscience, 6, 1-10. https://doi.org/10.3389/fnhum.2012.00114

Mercier, J., \& Charland, P. (submitted). Re-examining tutoring as a multiagent monitoring and regulation process from a cognitive and affective neuroscience point of view. Mind, Brain, \& Education.

Mercier, J., Léger, P. M., Girard, C., \& Dion, J.-S. (2012). Bridging the gap between cognitive neuroscience and education: Psychophysiological and behavioral data collection in authentic contexts. Neuroeducation, 1(1), 5-28. https://doi.org/10.24046/neuroed.20120101.5

Mikulka, P. J., Scerbo, M. W., \& Freeman, F. G. (2002). Effects of a biocybernetic system on vigilance decrement. Human Factors, 44(4), 654-664. https://doi.org/10.1518/0018720024496944

Newell, A. (1990). Unified theories of cognition. Cambridge, MA: Harvard University Press.

Offenloch, K., \& Zahner, G. (1990). Computer aided physiological assessment of the functional state of pilots during simulated flight. NATO Advisory Group for Aerospace Research and Development Conference Proceedings, 490, 1-9.

Parasuraman, R., Christensen, J., \& Grafton, S. (2012). Neuroergonomics: The brain in action and at work. Neurolmage, 59(1), 1-3. https://doi.org/10.1016/j.neuroimage.2011.08.011

Pope, A. T., Bogart, E. H., \& Bartolome, D. S. (1995). Biocybernetic system evaluates indices of operator engagement in automated task. Biological Psychology 40(1-2), 187-195. https://doi.org/10.1016/03010511(95)05116-3

Posner, M. I. (2012). Expanding horizons in ergonomics research. Neurolmage, 59(1), 149-153. https://doi.org/10.1016/..neuroimage.2011.07.060

Roach, B. J., \& Mathalon, D. H. (2008). Event-related EEG time-frequency analysis: An overview of measures and an analysis of early gamma band phase locking in schizophrenia. Schizophrenia Bulletin, 34(5), 907-926. https://doi.org/10.1093/schbul/sbn093 
Salas, E., Cook, N. J., \& Rosen, M. A. (2008) On teams, teamwork, and team performance: Discoveries and developments. Human Factors: The Journal of the Human Factors and Ergonomics Society, 50(3), 540547. https://doi.org/10.1518/001872008x288457

Stevens, R. H., Galloway, T. L., Berka, C., \& Behneman, A. (2010). Identification and application of neurophysiologic synchronies for studying the dynamics of teamwork. Paper presented at the Behavior Representation in Modeling \& Simulation (BRIMS) Conference.

Stevens, R. H., Galloway, T. L., Wang, P., \& Berka, C. (2011). Cognitive neurophysiologic synchronies: what can they contribute to the study of teamwork? Human Factors: The Journal of the Human Factors and Ergonomics Society, 54(4), 489-502.

https://doi.org/10.1177/0018720811427296

Stikic, M., Johnson, R. R., Levendowski, D. J., Popovic, D. P., Olmstead, R. E., \& Berka, C. (2011). EEG-derived estimators of present and future cognitive performance. Frontier in Human Neuroscience, 5, 1-13. https://doi.org/10.3389/fnhum.2011.00070

Sun, R. (2006). Prolegomena to integrating cognitive modeling and social simulation. In R. Sun (Ed.). Cognition and multi-agent interaction (pp. 3-26). New York, NY: Cambridge University Press. https://doi.org/10.1017/cbo9780511610721.002

Turner, D. A. (2012). Education and neuroscience. Contemporary Social Science, 7(2), 167-179. https://doi.org/10.1080/21582041.2012.692096

VanLehn, K. (2011). The relative effectiveness of human tutoring, intelligent tutoring systems, and other tutoring systems. Educational Psychologist, 46(4), 197-221. https://doi.org/10.1080/00461520.2011.611369

Warner, N., Letsky, M., \& Cowen, M. (2005). Cognitive model of team collaboration: Macro-cognitive focus. Proceedings of the Human Factors and Ergonomics Society Annual Meeting, 49(3), 269-273. https://doi.org/10.1177/154193120504900312

Wood, H., \& Wood, D. (1999). Help seeking, learning and contingent tutoring. Computers \& Education, 33(2-3), 153-169. https://doi.org/10.1016/s0360-1315(99)00030-5 